\title{
Non-syndromic hypodontia (NSH) in permanent teeth - epidemiological study
}

\author{
Hipodonția nonsindromică a dinților permanenți - studiu epidemiologic
}

\begin{tabular}{|c|}
\hline $\begin{array}{l}\text { Ioana-Andreea Stanciư }{ }^{1} \text {, Mihaela Tănase }{ }^{1} \text {, Rodica Luca1, } \\
\text { Daciana-Diana-Daniela Zmărăndache }{ }^{1}, \text { Maria-Cristina Ionică², Aneta Munteanu' }\end{array}$ \\
\hline $\begin{array}{c}{ }^{1} \text { Disciplina de Pedodonție, Facultatea de Medicină Dentară, UMF "Carol Davila“, București, România } \\
\text { 2Practică privată, București, România }\end{array}$ \\
\hline
\end{tabular}

\begin{abstract}
Aim. Assessment of characteristics of non-syndromic hypodontia (NSH) in permanent teeth (PT) in a group of Romanian children and adolescents.

Material and method. Descriptive retrospective observational study on dental files and orthopantomograms of 138 patients (59 boys) aged between 5-17 years (mean age $=11.96 \pm 3.13$ years) from Pedodontics Clinic Bucharest and from 3 private clinics. The topography of hypodontia, number of missing teeth and their distribution according to age and sex were assessed. Statistical analysis was performed using SPSS $20.0(p<0.05)$.

Results. The most cases were diagnosed at the age of $9-12$ years $(44.92 \%) .42 .76 \%$ of the missing teeth were in boys and $57.24 \%$ in girls, with boys:girls ratio $=1: 1.32$. $44.2 \%$ of patients had hypodontia in the mandible, $36.2 \%$ - in maxilla and $19.6 \%$ - in both arches simultaneosly; $50 \%$ in lateral area, $41.3 \%$ in front area and $8.7 \%$ in both areas. $75.30 \%$ of patients had $1-2$ missing teeth, with mean value of 2.02 missing teeth/patient (1.98/boys and $2.05 /$ girls, NS, $p>0.05)$. The most frequent teeth affected by NSH were second lower premolars $(37.27 \%)$, followed by upper lateral incisors $(29.75 \%)$ and upper second premolars $(16.48 \%)$.

Conclusions. In the study sample reduced unilateral lower hypodontia was most frequent. Early diagnose of $\mathrm{NSH}$ is important in order to apply specific treatments as quickly as possible, ensuring the harmonious growth and development of the dento-maxillary apparatus.
\end{abstract}

Keywords: non-syndromic hypodontia, permanent teeth, children, adolescents

\section{REZUMAT}

Scop. Evaluarea particularităților hipodonției nonsindromice (HNS) a dinților permanenți (DP) la un grup de copii și adolescenți din România.

Material şi metodă. Studiu retrospectiv observațional descriptiv pe fișele de observație și ortopantomogramele

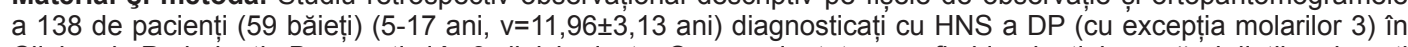
Clinica de Pedodonție București și în 3 clinici private. S-au evaluat: topografia hipodonţiei, numărul dinţilor absenţi şi distribuţia în funcţie de vârstă și sex. Analiza statistică s-a realizat cu programul SPSS $20.0(p<0,05)$.

Rezultate. Cele mai multe cazuri de HNS au fost diagnosticate la grupa de vârstă $9-12$ ani $(44,92 \%) .42,76 \%$ dintre dinții absenți au fost la băieți și 57,24\% la fete, cu un raport băieți:fete = 1:1,32. 44,2\% dintre pacienți aveau hipodonție la mandibulă, $36,2 \%$ - la maxilar și 19,6\% - la ambele arcade simultan; $50 \%$ pe zona laterală, $41,3 \%$ pe zona frontală și $8,7 \%$ pe ambele zone. $75,30 \%$ dintre pacienți au avut $1-2$ dinți absenți, cu o medie de 2,02 dinți absenți/pacient (1,98/băiat și 2,05/fată, NS, p > 0,05). Dinții cel mai frecvent absenți prin anodonție au fost premolarii doi inferiori $(37,27 \%)$, urmați de incisivii laterali superiori $(29,75 \%)$ și de premolarii doi superiori $16,48 \%$ ). Concluzii. La lotul studiat, cel mai frecvent s-a întâlnit hipodonția redusă mandibulară unilaterală. Este importantă diagnosticarea precoce a HNS pentru a se putea interveni cât mai rapid posibil prin tratamente specifice, asigurând creșterea și dezvoltarea armonioasă a aparatului dento-maxilar.

Cuvinte cheie: hipodonție nonsindromică, dinți permanenți, copii, adolescenți

\section{INTRODUCERE}

Hipodonţia este definită ca absența congenitală a 1,2 până la 5 dinți. Cunoașterea caracteristicilor acesteia în dentiţia permanentă prezintă o impor- tanță majoră pentru domeniul pedodonției. Diagnosticul precoce al acestei anomalii de număr este esențial pentru planificarea și iniţierea unui tratament optim, care, adesea, este complex și va- 
riabil în funcție de forma clinică, cuprinzând de la tratament ortodontic sau restaurări unidentare până la intervenții chirurgicale și restaurări multiple, necesitând astfel o abordare multidisciplinară, cu urmărire pe termen lung [1]. În acest sens, se impune un examen clinic atent, coroborat cu screening radiologic, ca parte a programelor naționale de sănătate publică [2], respectând normele recomandate în Ghidul Academiei Europene de Stomatologie Pediatrică (EAPD, 2003) [3]. Pentru populația din România, există puține studii asupra hipodonției.

\section{SCOP}

În acest context, scopul prezentei lucrări a fost evaluarea particularităților caracteristice hipodonției dinților permanenți la un grup de copii și adolescenți din România.

\section{MATERIAL ŞI METODĂ}

S-a realizat un studiu retrospectiv observaţional descriptiv pe un lot de 138 de pacienți (59 băieți) cu vârsta cuprinsă între 5 și 17 ani (vârsta medie $=$ $11,96 \pm 3,13$ ani), la care s-a diagnosticat pe ortopantomogramă anodonție la cel puțin un dinte permanent, cu excepția anodonției de molar 3.

Cazurile au fost selectate dintre pacienții care s-au prezentat la Clinica de Pedodonție, Facultatea de Medicină Dentară, UMF „Carol Davila“ București, și la 3 clinici private.

Datele au fost obținute din fișele de consultație și prin evaluarea radiografiilor panoramice ale pacienților. Radiografiile au fost examinate în condiții de iluminare optimă, iar pentru cele în format digital s-au utilizat parametrii standard de luminozitate și rezoluție a ecranului.

Criteriile de includere în lotul de studiu au fost: copii cu vârsta între 5 şi 17 ani, fără sindroame genetice sau despicături labio-maxilo-palatine, care prezintă andodonția a 1 până la 5 dinți permanenți (mai puțin molarii de minte).

Criteriile de excludere au fost: istoric de extracții dentare ca urmare a leziunilor carioase, traumatismelor, precum și istoric de extracții în scop ortodontic.

Din fișele de consultație, s-au obținut date privind: numele, sexul și vârsta pacienților, precum și statusul dentar. Pe radiografiile panoramice, s-au putut observa dinții prezenți în cavitatea bucală, dinții situați intraosos și s-a putut evalua prezența sau nu a anodonției.

S-a determinat repartiţia lotului de studiu în funcție de sex, de vârsta la care a fost diagnosticată anomalia și s-a evaluat distribuția dinților absenți prin anodonție în funcție de numărul de unități dentare afectate, topografie și arcada afectată. Prelucrarea statistică s-a realizat cu programul SPSS 20.0 pentru un nivel de semnificație statistică ales $\mathrm{p}<0,05$.

\section{REZULTATE}

\section{Distribuția pe sexe a pacienților incluşi în studiu}

Dintre cei 138 de pacienți diagnosticați cu hipodonție nonsindromică, 42,76\% erau băieți și $57,24 \%$ - fete. Raportul băieți:fete a fost de 1:1,32.

\section{Vârsta la care s-a depistat anomalia de număr}

Cele mai multe cazuri de hipodonție au fost depistate între 9 și 12 ani (fig. 1).

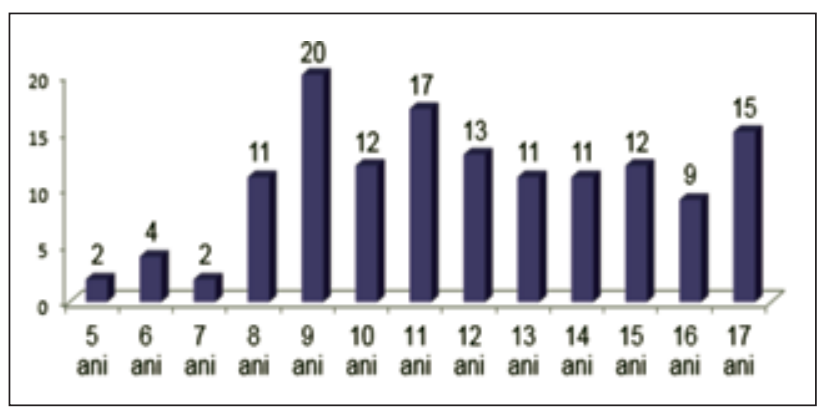

FIGURA 1. Distribuția lotului în funcție de vârsta depistării anomaliei ( $n=138$ pacienți)

\section{Distribuția pacienților în funcție de topografia hipodonției}

Pacienții au prezentat mai frecvent această anomalie la arcada mandibulară $-44,2 \%(n=61$ pacienți). Anodonția la arcada superioară s-a întânit la $36,2 \%$ dintre pacienţi $(n=50)$, în timp ce $19,6 \%$ dintre aceștia $(n=27)$ au prezentat simultan anodonția unor dinți de pe ambele arcade.

Anomalia s-a întâlnit mai frecvent în zona laterală - în 50\% dintre cazuri ( $n=69$ pacienți), comparativ cu zona frontală $-41,3 \%$ dintre pacienți $(\mathrm{n}=57)$. Doar 12 pacienți $(8,7 \%)$ au prezentat anodonție atât în zona frontală, cât și în zona laterală.

Cel mai des, dinții absenți au fost situați bilateral (63\% dintre cazuri). În 19,6\% dintre cazuri au 
fost numai pe partea dreaptă și în $17 \%$ - numai pe partea stângă.

\section{Distribuția pacienților în funcție de numărul unităților dentare afectate}

Cei mai mulți pacienți $(75,3 \%)$ au avut 1 sau 2 dinţi absenţi (fig. 2).

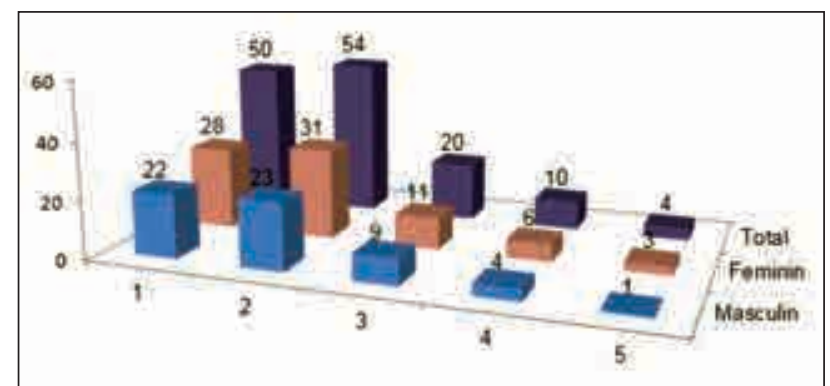

FIGURA 2. Distribuția lotului în funcție de numărul de dinți absenți $(n=138$ pacienți)

Au fost în total 279 de dinţi absenţi ca urmare a hipodonției (exclusiv molarii de minte), cu o medie de 2,02 dinți absenți/pacient. Băieții au avut în medie 1,98 dinţi absenți/pacient, iar fetele 2,05 , diferențele fiind nesemnificative statistic $(\mathrm{p}>0,05)$.

\section{Distribuția dinților în funcție de tipul unității dentare afectate}

Premolarii secunzi inferiori au fost cei mai afectați de anodonție (37,27\%), urmaţi de incisivii laterali superiori $(29,75 \%)$ și de premolarii 2 superiori $(16,48 \%)$. Cel mai puțin interesați au fost caninii și molarii unu (fig. 3). Pentru toate unităţile dentare afectate, cu excepția incisivilor centrali inferiori, agenezia a fost mai frecventă la sexul feminin.

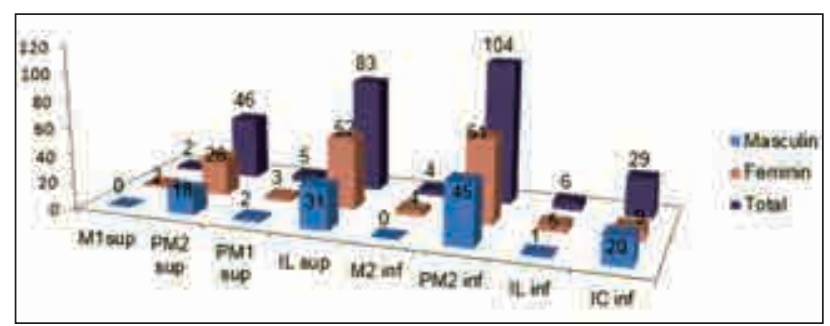

FIGURA 3. Distribuția dinților în funcție de tipul unității dentare afectate $(n=279$ dinți)

\section{Distribuția dinților absenți în funcție de localizare}

Dinţii absenţi ca urmare a ageneziei au fost mai frecvent localizați în zona laterală - în proporție de $56,98 \%$, iar în zona frontală de $43,02 \%$, diferențele fiind semnificative statistic $(\mathrm{p}<0,05)$.
Dintre cei 279 de dinţi absenți congenital, 136 $(48,75 \%)$ au fost localizaţi la maxilar și 143 $(51,25 \%)$ la mandibulă, diferentele fiind nesemnificative statistic $(p>0,05)$. De asemenea, 134 $(48,03 \%)$ au fost situați pe partea dreaptă și 145 $(51,97 \%)$ pe partea stângă. Nici în acest caz diferențele nu au fost semnificative statistic $(p>0,05)$.

\section{DISCUȚII}

Hipodonția a fost raportată ca fiind una dintre cele mai frecvente anomalii dentare la om [4-7]. O metaanaliză recentă a studiilor care au analizat hipodonţia în dentiţia permanentă, pe loturi cu un număr variabil de subiecți, de la 200 până la 100.000 , a arătat o prevalență a anomaliei cuprinsă între $0,15 \%$ și $16,2 \%$, excluzând anodonţia de molar de minte. În funcție de rasă și continent, frecvența hipodonției este diferită: Asia 0,2-16,2\%; Australia 5,9-6,4\%; Europa 2,3-15,7\%; America de Nord 2,7-7,8\%; America de Sud 4,8-6,3\% (Rakhsha şi colab., 2015 [7]. Se consideră că prevalența absenței congenitale a dinților ar putea crește ca urmare a modificărilor evolutive sau a unei rate mai mari de diagnosticare, însă acest lucru nu este confirmat încă pentru ultimele decenii de către metaanalizele existente cu privire la hipodonție [7-9].

În prezentul studiu, sexul feminin (57\%) a fost mai afectat de anodonție decât sexul masculin (43\%), observație susținută şi de alte studii. Astfel, Aktan şi colab. (Turcia, 2010) au raportat o frecvență mai mare a anodonției la fete $(57,85 \%)$ față de băieți $(42,15 \%)$ [10]. Și Țărmure (Cluj-Napoca, România, 2017) a constatat că $69 \%$ dintre copiii și adolescenții cu hipodonție examinați erau de sex feminin, iar $31 \%$ de sex masculin [11]. În contrast, Georgescu și colab. (București, România, 2019), într-un studiu efectuat pe ortopantomograme, au găsit că $63,63 \%$ dintre cazurile de hipodonție erau la băieți, în timp ce doar $36,36 \%$ erau la fete [3].

Raportul băieți:fete găsit în prezentul studiu a fost de 1:1,32, apropiat de cele raportate în literatura de specialitate (valori între 1:1,37 și 1:1,4) $[8,12,13]$. Frecvența mai mare întâlnită la sexul feminin este asociată de Rakhshan şi colab. (2015) [7] diferențelor biologice, cum ar fi prezența unor maxilare mai înguste. Unele studii $[14,15]$ au găsit însă o predominanţă mai mare a anodonției la 
sexul masculin, iar Silva și colab. (Mexic, 2003) [16], Chung și colab. (Coreea, 2008) [17]panoramic radiographs, and lateral cephalograms of 1622 Korean subjects (611 males, 1011 females și Behr și colab. (Germania, 2011) [18] au găsit valori egale ale frecvenței anodonției pentru cele două sexe.

Media dinților absenți prin agenezie/pacient a fost 2,02, valoare care se încadrează în intervalul raportat în literatura de specialitate 1,5-4,8 [19,20] (tabelul 1).

În ceea ce privește media dinților absenți/pacient în funcție de sex, s-a găsit o diferență nesemnificativă statistic între sexe: 1,98 dinți absenți/băiat și 2,05 dinți absenți/fată. Datele din literatura de specialitate sunt contradictorii. Astfel, Backman (Suedia, 2001) [4] a raportat valori de 1,46 dinți absenți/băiat și 1,74 dinți absenți/fată. Pe de altă parte, Amini și colab. (Iran, 2012) în comparație cu numărul mediu de dinți absenți/fată $(1,40)$ [12]. Endo și colab. (Japonia, 2006) au găsit însă rezultate aproximativ egale: 2,5 dinți absenți/băieți și 2,4 dinți absenți/fete [5], ca și Silva și colab. [16] (Mexic, 2003) și Behr și colab. [18] (Germania, 2011)

Un aspect important pentru studiile asupra hipodonției este vârsta de diagnosticare, deoarece vizibilitatea germenilor dentari pe radiografii depinde de stadiul de mineralizare al dinţilor. Există diferențe majore între stadiile de mineralizare și vârsta dentară pentru subiecți de aceeași vârstă cronologică. O atenție deosebită trebuie acordată mugurilor dentari cu declanșare tardivă a mineralizării (precum premolarii doi mandibulari), diagnosticul de anodonție stabilindu-se după o perioadă de timp astfel incât să nu apară diagnostice fals pozitive [8]. În prezentul studiu, vârsta cea mai frecventă de depistare a pacienților cu anodonție a fost 9 ani, urmată de vârsta de 11 ani. De asemenea, Acev și colab. (Macedonia, 2014) [2] și Tunç și colab. (Turcia, 2011) [21] au constatat că au fost diagnosticate cele mai multe cazuri la vârsta de 9 ani. În schimb, Gokkaya și colab. (Turcia, 2015) [1] au găsit că, cel mai frecvent, pacienții cu hipodonție s-au prezentat pentru prima dată în clinica de ortodonție la vârsta de 12 ani.

Raportat la localizarea anodonţiei, în studiul prezent, s-a evidenţiat că arcada mandibulară a fost mai frecvent afectată de anodonție - în 44,2\% dintre cazuri, comparativ cu arcada maxilară $36,2 \%$ sau cu ambele arcade $-19,6 \%$. În literatura de specialitate, nu există un consens cu privire la arcada mai frecvent afectată. Astfel, Chung și colab. (Coreea, 2008) [17], asemănător studiului prezent, au raportat o afectare considerabil mai mare a arcadei mandibulare - 49,5\% dintre subiecți, în comparație cu arcada maxilară $-29,1 \%$ sau cu localizarea simultană la ambele arcade 21,4\%. Acev și colab. (Macedonia, 2014) [2] au găsit următoarea distribuție a cazurilor: mandibulă -43,97\%, maxilar - 38,11\%, maxilar și mandibulă - 17,92\%. In contrast, studiul lui Gungor și colab. (Turcia, 2013) [22] relevă o prevalență diferită a afectării prin hipodonție a celor două arcade: $55,19 \%$ dintre cazuri - simultan la ambele arcade, $24,03 \%$ - la arcada maxilară, $20,78 \%$ - la arcada mandibulară. Sheikhi și colab. (Iran, 2012) [23] au găsit o prevalență mai mică pentru absența congenitală a dinților la arcada mandibulară $(43,2 \%)$, în comparație cu cea maxilară $(56,8 \%)$, rezultate similare înregistrând și Sisman și colab. (Turcia, 2007) [24], Amini și colab. (Iran, 2012) [12] Fekonja (Slovenia, 2005) [25].

Jumătate dintre pacienții din studiul prezent prezentau anodonție în zona laterală a arcadelor, iar $41,3 \%$ în zona frontală, in timp ce $8,7 \%$ dintre cazuri au prezentat anodonție simultan în zona frontală și laterală. De asemenea, Aasheim și colab. (Norvegia, 1993) au observat că, la 66\% dintre pacienți, anodonțiile erau în zona laterală, în $30,7 \%$ dintre cazuri în zona frontală și 3,1\% în ambele zone [26]. În schimb, Ng'ang'a (Kenya, 2001) a raportat $54 \%$ dintre cazuri în zona frontală, $32 \%$

TABEL 1. Media de dinți absenți congenital/pacient/sex - date comparative

\begin{tabular}{|l|c|c|c|c|}
\hline Autor/An studiu & Țara & Lot & $\begin{array}{c}\text { Vârsta } \\
\text { (ani) }\end{array}$ & $\begin{array}{c}\text { Media dinți } \\
\text { absenți/copil }\end{array}$ \\
\hline Chung și colab. [17] (2008) & Coreea & 182 & - & 1,8 \\
\hline Goya și colab. [6] (2008) & Japonia & 2072 & $3-17$ & 2,8 \\
\hline Acev și colab. [2] (2014) & Macedonia & 8160 & $8-18$ & 2,04 \\
\hline Aktan și colab. [10] (2010) & Turcia & 1471 & - & 2,14 \\
\hline Amini și colab. [12] (2012) & Iran & 3374 & $10-20$ & 1,69 \\
\hline Studiul prezent (2020) & România & 138 & $5-17$ & 2,02 \\
\hline
\end{tabular}


în zona laterală și $8 \%$ pe ambele zone [15]. Şi alte studii au găsit o prevalență mai mare pentru anodonție în zona anterioară a arcadelor dentare [12,27]. Endo și colab. (Japonia, 2006) [5] au stabilit o legătură între zona dentară mai frecvent afectată de hipodonţie şi severitatea anomaliei. Astfel, pacienții cu hipodonție minoră (1 sau 2 dinţi lipsă) au prezentat absenţa dinţilor preponderent în zona frontală, iar, odată cu creșterea severităţii hipodonției, au fost mai frecvent absenţi dinţii cu localizare posterioară.

Raportat la dinţii absenți prin agenezie, metaanaliza lui Polder și colab. (2004) [8] a aratat că, ditre cei 11.422 de dinți absenți congenital, 30,74\% erau în zona frontală și $69,26 \%$ în zona laterală. În studiul lui Amini și colab. (Iran, 2012) [12] 60,75\% dintre dinții cu agenezie erau din zona laterală, iar $39,24 \%$ din zona frontală, în studiul lui Sisman și colab. (Turcia, 2007) [24] - 57,56\% din zona laterală, 42,44\% din zona frontală, în studiul lui Behr și colab. (Germania, 2011) [18] - 62,7\% din zona posterioară, $37,3 \%$ din zona anterioară. Doar Vahi-Dastjerdi și colab. (Iran, 2010) [27] au găsit o prevalență mai mare a dinților absenți în zona frontală - aproximativ $60 \%$.

În ceea ce privește distribuția pacienților cu hipodonţie în funcție de hemiarcada afectată, s-a obținut că $63 \%$ dintre pacienți au prezentat anodonție bilaterală, în timp ce $19,6 \%$ au prezentat hipodonție pe partea dreaptă, iar $17,6 \%$ pe partea stângă. Kielan-Grabowska și colab. (Polonia, 2019) au raportat o predominanţă mai mare a pacienților cu anodonție pe ambele părți ale arcadelor dentare $(48,7 \%)$ comparativ cu partea stângă $(37,2 \%)$ și, respectiv, dreaptă $(14,1 \%)$ [28].

Majoritatea pacienților $(75,3 \%)$ aveau 1 sau 2 dinți absenți, rezultat aflat în concordanță cu cele obținute în studii anterioare. Astfel, absența a 1-2 dinți a fost întâlnită în procent de 76,3\% de Endo și colab. (Japonia, 2006) [5], de 79,6\% de către Chung și colab. (Coreea, 2008) [17], 82,96\% de
Sisman și colab. (Turcia, 2007) [24] și de $87 \%$ de Sheikhi și colab. (Iran, 2012) [23]. Alte studii au găsit valori inferioare pentru hipodonția redusă $[4,15,24,26]$, cea mai mică valoare, de $49 \%$, fiind obținută de Lai și Seow [20]. Metaanaliza efectuată de Polder şi colab. [8] a arătat că, în 48\% dintre cazuri, pacienților le-a lipsit un singur dinte, iar $38 \%$ dintre pacienți au avut hipodonție de doi dinţi.

Hipodonția a fost întâlnită cel mai frecvent la premolarii doi inferiori, urmați de incisivii laterali superiori, premolarii doi superiori și incisivii inferiori. Această secvență corespunde cu cea găsită ca fiind cea mai frecventă de către Polder şi colab. [8] şi de către Partovi și colab. (Iran, 2002) [29]. Alte studii au găsit însă o secvență diferită a frecvenței. Spre exemplu, Sisman și colab. (Turcia, 2007) [24] au găsit următoarea ordine: Ilsup $>$ PM2inf $>$ PM2 sup >Iinf. Georgescu și colab. (România, 2019) [3] au raportat: PM2inf $>$ Icinf drept $>$ Ilsup, iar Nordgarden și colab. (Norvegia, 2002) [30]: PM2inf $>$ PM2sup $>$ Ilsup $>$ Iinf. Endo și colab. (Japonia, 2006) [5] au observat o frecvență a dinților absenți diferită în funcție de numărul de dinţi lipsă: pentru pacienții cu 1-2 dinţi lipsă PM2inf $>$ Ilsup/ILinf; pentru pacienții cu 3-4 dinţi lipsă - PM2inf $>$ PM2sup $>$ IL; pentru pacienții cu 5 sau mai mulți dinți lipsă - PM2inf $>$ PM2sup>PM1 .

Dinții cu cea mai mică prevalență a anodonției au fost, în ordine crescătoare: M1sup $(0,72 \%)$, M2inf (1,43\%), PM1sup (1,79\%) şi ILinf (2,14\%). Pentru M2sup, M1 inf, Csup, Cinf și ICsup nu s-au găsit cazuri de anodonție.

În literatura de specialitate, nu există o ordine consacrată pentru dinții cel mai puțin afectați de anodonţie, însă, în cele mai multe studii, molarii unu s-au găsit ca fiind cei mai stabili dinţi (tabelul 2).

\section{CONCLUZII}

La lotul studiat, cei mai mulți pacienți au avut 1 sau 2 dinţi absenți congenital, de regulă bilateral și cel mai frecvent pe zona laterală.

TABEL 2. Dinții cel mai rar afectați de agenezie congenitală - prevalență

\begin{tabular}{|c|c|c|c|c|c|c|c|c|}
\hline $\begin{array}{l}\text { Autori/ } \\
\text { An studiu }\end{array}$ & Țară & $\begin{array}{c}\text { M1sup } \\
\%\end{array}$ & $\begin{array}{c}\text { M1inf } \\
\%\end{array}$ & $\begin{array}{c}\text { M2sup } \\
\%\end{array}$ & $\begin{array}{c}\text { M2inf } \\
\%\end{array}$ & $\begin{array}{c}\text { Cinf } \\
\%\end{array}$ & $\begin{array}{c}\text { Icsup } \\
\%\end{array}$ & $\begin{array}{c}\text { Csup } \\
\%\end{array}$ \\
\hline Chung și colab. [17] (2008) & Coreea & 0 & 0 & 0,6 & 1,2 & 1,5 & 1,5 & - \\
\hline Polder și colab. [8] (2004) & Metaanaliză & 0,7 & 0,3 & 0,6 & - & 0,3 & 0,2 & - \\
\hline Sisman și colab. [24] (2007) & Turcia & 0,74 & 0,96 & 0,2 & 0,2 & 0,37 & 0,41 & 0,33 \\
\hline Studiul prezent (2020) & România & 0,72 & 0 & 0 & 1,43 & 0 & - & 0 \\
\hline
\end{tabular}


Este foarte importantă diagnosticarea precoce a hipodonției astfel încât să se poată interveni cât mai rapid posibil prin tratamente specifice care să asigure creșterea și dezvoltarea aparatului dentomaxilar cât mai aproape de parametrii normali vârstelor interesate.

\section{BIBLIOGRAFIE}

1. Gökkaya B, Motro M, Kargül B. Prevalence and characteristics of non-syndromic hypodontia among Turkish orthodontic patient population. J Int Soc Prev Community Dent. 2015;5(3):170-5.

2. Acev DP, Gjorgova J. Prevalence of Hypodontia in the Permanent Dentition of Macedonian Population. Balk J Dent Med. 2014; 18(2):93-8.

3. Georgescu DE, Georgescu EM, Luca R. Prevalența și distribuția anomaliilor dentare de dezvoltare - studiu ortopantomografic. Ro J Stomatol. 2019;65(4):389-94.

4. Bäckman B, Wahlin YB. Variations in number and morphology of permanent teeth in 7-year-old Swedish children. Int J Paediatr Dent. 2001;11(1):11-7.

5. Endo T, Ozoe R, Kubota M et al. A survey of hypodontia in Japanese orthodontic patients. Am J Orthod Dentofacial Orthop. 2006; 129(1):29-35.

6. Goya HA, Tanaka S, Maeda T et al. An orthopantomographic study of hypodontia in permanent teeth of Japanese pediatric patients. J Oral Sci. 2008;50(2):143-50.

7. Rakhshan V. Congenitally missing teeth (hypodontia): A review of the literature concerning the etiology, prevalence, risk factors, patterns and treatment. Dent Res J. 2015;12(1):1-13.

8. Polder BJ, Van't Hof MA, Van der Linden FP et al. A meta-analysis of the prevalence of dental agenesis of permanent teeth. Community Dent Oral Epidemiol. 2004;32(3):217-26.

9. Rakhshan V. Meta-analysis and systematic review of factors biasing the observed prevalence of congenitally missing teeth in permanent dentition excluding third molars. Prog Orthod. 2013;14(1):33.

10. Aktan AM, Kara IM, Şener İ et al. Radiographic study of tooth agenesis in the Turkish population. Oral Radiol. 2010;26(2):95-100.

11. Țărmure V. Oral interdisciplinary rehabilitation in the context of numerical deficit dental abnormalities. Romanian J Oral Rehabil. 2017;9(4):78-83.

12. Amini F, Rakhshan V, Babaei P. Prevalence and pattern of hypodontia in the permanent dentition of 3374 Iranian orthodontic patients. Dent Res J. 2012;9(3):245-50.

13. Wu CCL, Wong RWK, Hagg EUO. A review of hypodontia: the possible etiologies and orthodontic, surgical and restorative treatment options: conventional and futuristic. Hong Kong Dent $\mathrm{J}$. 2007;4:113-21.

14. Gupta SK, Saxena P, Jain S et al. Prevalence and distribution of selected developmental dental anomalies in an Indian population. J Oral Sci. 2011;53(2):231-8.

15. Ng'ang'a RN, Ng'ang'a PM. Hypodontia of permanent teeth in a Kenyan population. East Afr Med J. 2001;78(4):200-3.

\section{Notă}

Autorii au contribuit în mod egal la prezentul articol, de aceea toți sunt considerați autori principali.

\section{Conflict of interest: none declared} Financial support: none declared

16. Silva MR. Radiographic assessment of congenitally missing teeth in orthodontic patients. Int J Paediatr Dent. 2003;13(2):112-6.

17. Chung CJ, Han J-H, Kim K-H. The pattern and prevalence of hypodontia in Koreans. Oral Dis. 2008;14(7):620-5.

18. Behr M, Proff $P$, Leitzmann $M$ et al. Survey of congenitally missing teeth in orthodontic patients in Eastern Bavaria. Eur J Orthod. 2011;33(1):32-6.

19. Davis PJ. Hypodontia and hyperdontia of permanent teeth in Hong Kong schoolchildren. Community Dent Oral Epidemiol. 1987; 15(4):218-20.

20. Lai PY, Seow WK. A controlled study of the association of various dental anomalies with hypodontia of permanent teeth. Pediatr Dent. 1989;11(4):291-6.

21. Tunç EŞ, Bayrak Ş, Koyutürk AE. Dental development in children with mild-to-moderate hypodontia. Am J Orthod Dentofacial Orthop. 2011;139(3):334-8.

22. Gungor AY, Turkkahraman $\mathrm{H}$. Effects of severity and location of nonsyndromic hypodontia on craniofacial morphology. Angle Orthod. 2013; 83(4):584-90.

23. Sheikhi M, Sadeghi MA, Ghorbanizadeh S. Prevalence of congenitally missing permanent teeth in Iran. Dent Res J. 2012; 9(1):105-11.

24. Sisman Y, Uysal T, Gelgor IE. Hypodontia. Does the prevalence and distribution pattern differ in orthodontic patients? Eur J Dent. 2007;1(3):167-73.

25. Fekonja A. Hypodontia in orthodontically treated children. Eur J Orthod. 2005;27(5):457-60.

26. Aasheim B, Ögaard B. Hypodontia in 9-year-old Norwegians related to need of orthodontic treatment. Eur J Oral Sci. 1993; 101(5):257-60.

27. Vahid-Dastjerdi E, Borzabadi-Farahani A, Mahdian M, Amini N. Non-syndromic hypodontia in an Iranian orthodontic population. $J$ Oral Sci. 2010;52(3):455-61.

28. Kielan-Grabowska Z, Kawala B, Antoszewska-Smith J. Hypodontia - not only an orthodontic problem. Dent Med Probl. 2019; 56(4):373-7.

29. Partovi M, Mehranfar P. Prevalence of congenital missing of anterior and premolar permanent teeth among 12-17 year old people in Babol, 2000. Babol-Jbums. 2002;4(2):30-3.

30. Nordgarden H, Jensen JL, Storhaug K. Reported prevalence of congenitally missing teeth in two Norwegian counties. Community Dent Health 2002;19(4):258-61. 